\title{
Three new species of the genus Mimetus Hentz, 1832 (Araneae: Mimetidae) from Yunnan-Guizhou Plateau of China
}

\author{
Jiahui GAN ${ }^{1}$, Xiaoqi $\mathrm{MI}^{2}$, Muhammad IRFAN ${ }^{3}$, Xianjin $\mathrm{PENG}^{4, *}$, \\ Siyu RAN ${ }^{5} \&$ Ying ZHAN $^{6}$ \\ ${ }^{1,2}$ College of Agriculture and Forestry Engineering and Planning, Tongren University, \\ Tongren, Guizhou, 554300, China. \\ ${ }^{3,4}$ College of Life Sciences, Hunan Normal University, Changsha, Hunan, 410081, China. \\ 5,6 Fodingshan National Nature Reserve Administration, Tongren, Guizhou, 555100, China. \\ *Corresponding author: xjpeng@126.com \\ 1Email:605750307@qq.com \\ 2Email: 13692609@qq.com \\ ${ }^{3}$ Email: irfanuos94@yahoo.com \\ 5Email: 864293591@qq.com \\ 6Email: 735200624@qq.com \\ ${ }^{1}$ urn:lsid:zoobank.org:author:F8175C32-9605-4541-B247-7BBEF9FDE07D \\ ${ }^{2}$ urn:1sid:zoobank.org:author:B17FB420-A500-4145-83BE-E64700E7D6A7 \\ ${ }^{3}$ urn:lsid:zoobank.org:author:81552C4A-93FC-4B6E-8EA1-0B4E38CC6466 \\ ${ }^{4}$ urn:1sid:zoobank.org:author:61E0E8EE-1F50-447F-B75D-53B35F303236 \\ ${ }^{5}$ urn:lsid:zoobank.org:author:27377B72-E667-44F0-A3AC-74D485330B94 \\ ${ }^{6}$ urn:lsid:zoobank.org:author:A547A5D4-6AFF-4106-AB6E-D1933D3BAD0E
}

\begin{abstract}
Three new species of the genus Mimetus Hentz, 1832 are described and named as M. bucerus

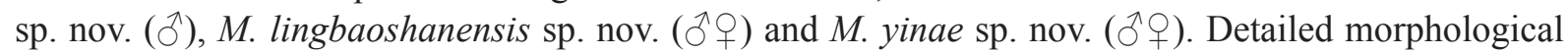
descriptions, photos of the body and copulatory organs, line drawings of copulatory organs, as well as the distribution maps are provided.
\end{abstract}

Keywords. Arachnids, China, morphology, pirate spiders, taxonomy.

Gan J., Mi X, Irfan M., Peng X., Ran S. \& Zhan Y. 2019. Three new species of the genus Mimetus Hentz, 1832 (Araneae: Mimetidae) from Yunnan-Guizhou Plateau of China. European Journal of Taxonomy 525: 1-13. https://doi.org/10.5852/ejt.2019.525

\section{Introduction}

Mimetus Hentz, 1832 is the most species-rich genus of the family Mimetidae Simon, 1881 and comprises about 55 species from all over the world except Australia and Antarctica (World Spider Catalog 2019). Up to now, there are 8 species recorded from China (Wang 1990; Liang \& Wang 1991; Song \& Zhu 1993; Zeng et al. 2016). 
Most of the species of Mimetus documented in the $19^{\text {th }}$ and $20^{\text {th }}$ century were described in that genus on the base of the somatic characters only. The principal features were: clypeus shorter than eye region; legs I and II longer than legs III and IV; carapace with low profile in lateral view. Characters of the genital organs were not taken into account. As a consquence, the status of some species of Mimetus needs further study. For example, M. sinicus Song \& Zhu, 1993 was described as a member of the genus Mimetus according to its somatic characters, while its genitalia closely resemble those of Ero japonica Bösenberg \& Strand, 1906 and might therefore belong to that genus.

Harms \& Dunlop (2009) redefined Mimetus on the base of the genitalia and this was confirmed in a phylogenetic analysis by Harms \& Harvey (2009). Important synapomorphies are the male palpal cymbium with a retrolateral sclerotized extension or 'shovel', and a terminal extension or 'vexillum'; the bulb with a number of sclerites which are specific for the genus. The female epigyne is subtriangular, strongly sclerotized, with inconspicuous posterior genital openings.

While examining the specimens of Mimetidae specimens collected from Yunnan-Guizhou Plateau of China, three new species of Mimetus were identified and are described here. The specimens are deposited in the Museum of Tongren University, Guizhou Province, China.

\section{Material and methods}

Descriptions were made based on specimens fixed in $75 \%$ ethanol. The specimens were examined and measured using an Olympus SZ30 stereo microscope. The details were studied with an Olympus BX53 compound microscope. Male palp and female genitalia were drawn after they had been dissected from the spiders. Photos were taken with a Canon PowerShot G12 digital camera mounted on an Olympus BX53. Compound focus images were generated using Helicon Focus software. The map was created by ArcMap 10.2, and modified using Adobe Photoshop CS2 Extended.

All measurements are given in millimetres. Leg measurements are giving as total length (femur, patella + tibia, metatarsus, tarsus).

\section{The abbreviations}

$\mathrm{AER}=$ anterior eye row
$\mathrm{ALE}=$ anterior lateral eye
$\mathrm{AME}=$ anterior median eye
$\mathrm{BP}=$ basal plate
$\mathrm{CD}=$ copulatory duct
$\mathrm{CO}=$ copulatory opening
$\mathrm{E}=$ embolus
$\mathrm{FD}=$ fertilization duct
$\mathrm{M}=$ membrane
$\mathrm{MOA}=$ median ocular area
$\mathrm{PC}=$ paracymbium
$\mathrm{PER}=$ posterior eye row
$\mathrm{PLE}=$ posterior lateral eye
$\mathrm{PME}=$ posterior median eye
$\mathrm{S}=$ spermatheca
$\mathrm{SC}=$ scape
$\mathrm{SH}=$ shovel
$\mathrm{ST}=$ subtegulum
$\mathrm{VE}=$ vexillum




\section{Results}

Class Arachnida Cuvier, 1812

Order Araneae Clerck, 1757

Family Mimetidae Simon, 1881

Genus Mimetus Hentz, 1832

Mimetus bucerus sp. nov.

urn:1sid:zoobank.org:act:D5CAEEF0-D171-45E9-A913-E391575E45E6

Figs $1-2,7$

\section{Differential diagnosis}

The male of this new species resembles that of $M$. lingbaoshanensis sp. nov., but can be distinguished from the latter by: 1) vexillum of male palp ox-horned in retrolateral view (Figs 1C, 2B) versus handlelike in M. lingbaoshanensis sp. nov. (Figs 3C, 4B); 2) distal portion of paracymbium claviform in retrolateral view (Figs 1C, 2B) versus lamelliform in M. lingbaoshanensis sp. nov. (Figs 3C, 4B); 3) tibia about 2 times longer than cymbium (Figs 1C, 2B) versus as long as cymbium in M. lingbaoshanensis sp. nov. (Figs 3C, 4B).

\section{Etymology}

The specific name comes from the Latin 'bucerus' ('ox-horned'), refers to the shape of the vexillum of the cymbium.

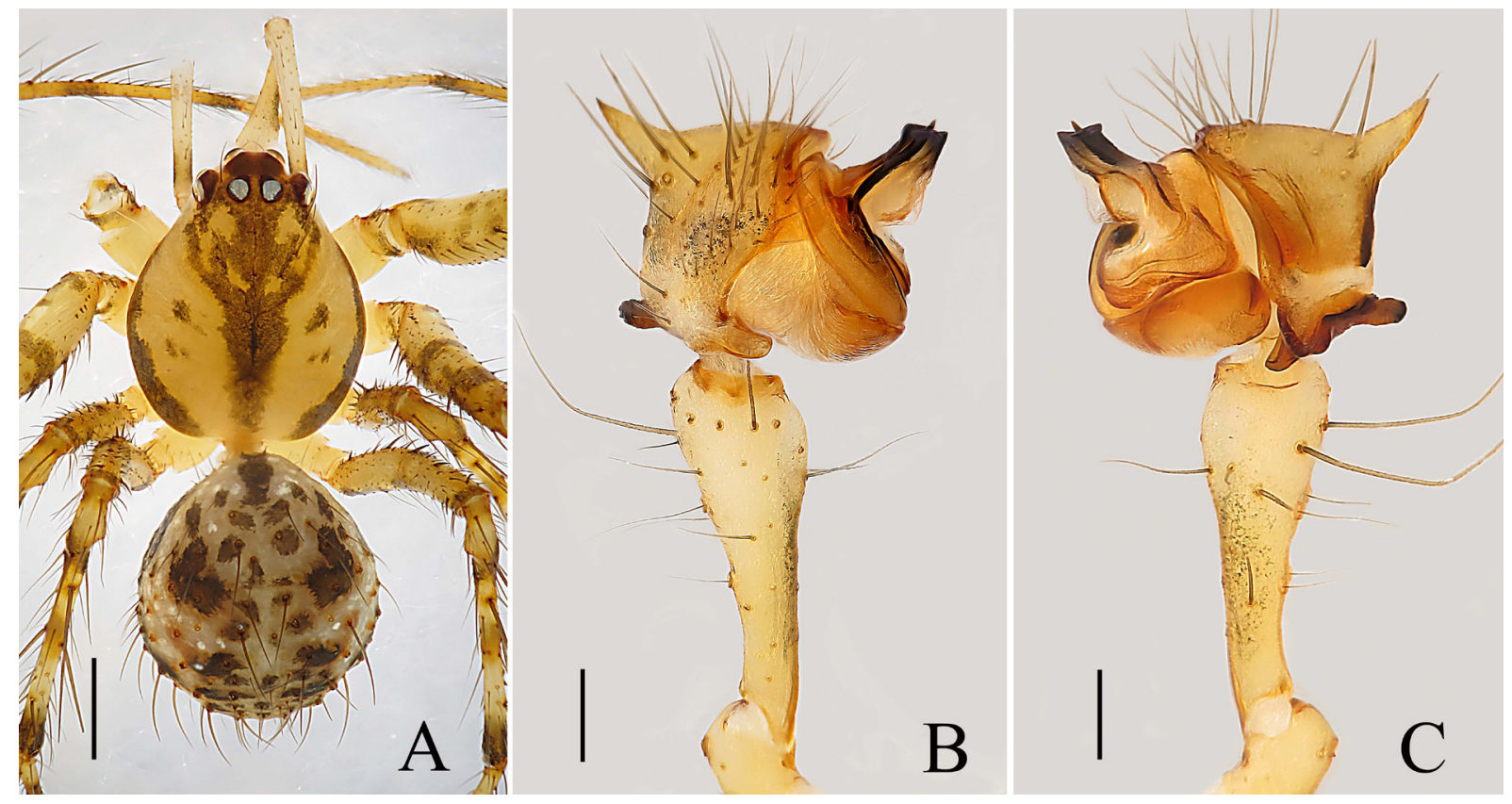

Fig. 1. Mimetus bucerus sp. nov. A-C. Holotype, $ð$ (GZ-MIM-2017-005). A. Habitus, dorsal view. B. Palp, prolateral view. C. Palp, retrolateral view. Scale bars: A $=1.0 \mathrm{~mm} ; \mathrm{B}-\mathrm{C}=0.1 \mathrm{~mm}$. 


\section{Type material}

\section{Holotype}

CHINA - ô; Guizhou, Tongren city, Leishan County, Leigongshan National Nature Reserve, Xiangshuiyan; 2622'24" N, 108 $12^{\prime} 20^{\prime \prime}$ E; 1642.1 m; 21 Jul. 2017, Cheng Wang, Feng-e Li, Gui-jie Tian and Hong Liu leg.; GZ-MIM-2017-005.

\section{Description}

Male (holotype)

MeAsurements. Total length 2.92.

Prosoma. 1.51 long, 1.32 wide, pear-like, yellow, with a longitudinal brown band, fovea oval, situated posteriorly (Fig. 1A),

CLYPeus. 0.15 high.

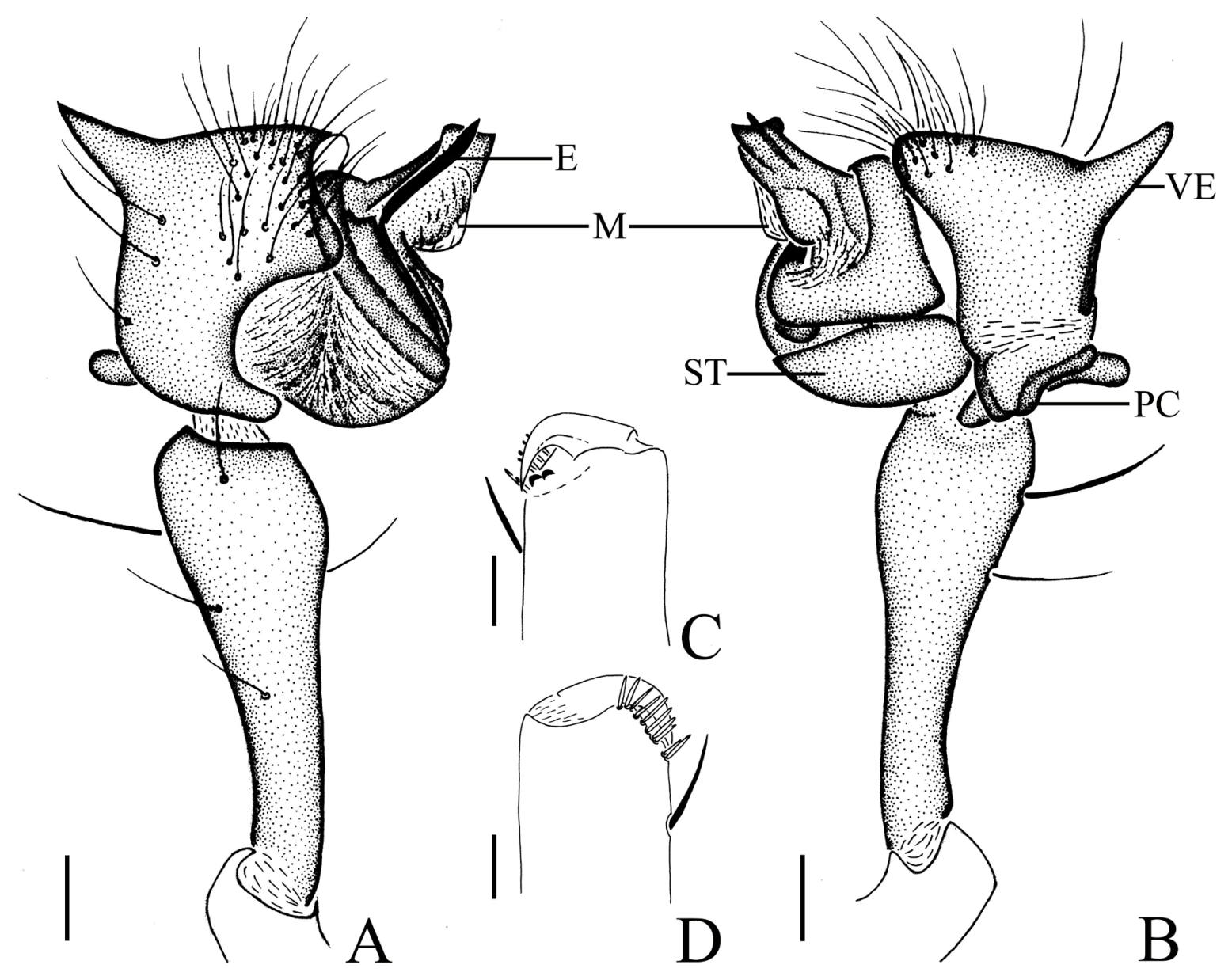

Fig. 2. Mimetus bucerus sp. nov. A-D. Holotype, $\widehat{\jmath}$ (GZ-MIM-2017-005). A. Palp, prolateral view. B. Palp, retrolateral view. C. Left chelicerae of male,ventral view. D. Left chelicerae, dorsal view. Scale bars: $0.1 \mathrm{~mm}$. 
EYE. Sizes and interdistances: AME 0.14, ALE 0.09, PME 0.11, PLE 0.10, AME-AME 0.13, ALE-AME 0.14, PME-PME 0.98, PME-PLE 0.17. MOA anterior width 0.49, posterior width 0.51 , length 0.52 .

Chelicerae (Figs 2C-D). Red-brown, with 10 promarginal peg setae and 2 retromarginal teeth. Endites light yellow, longer than wide. Labium light yellow, longer than wide. Sternum pear-shaped, glabrous, colouration as labium except for margin with few macrosetae.

LEGS. Slim, spiniferous, with brown patches. Length of legs: I 9.25 (2.51, 3.22, 2.41, 1.11), II 6.70 (1.89, 2.22, 1.58, 1.01), III $4.12(1.28,1.23,0.82,0.79)$, IV $4.97(1.70,1.45,1.01,0.81)$. Leg formula: 1243.

Opisthosoma. 1.43 long, 1.31 wide, oval, with irregular red-brown patches and white spots, covered with sparse long hairs (Fig. 1A); ventral side with three brown patches, median area glabrous and grey, both sides with white spots.

PaLP (Figs 1B-C, 2A-B). Cymbium slightly domed, with a ox-horned vexillum and several long hairs at the apex (Figs 1B-C, 2A-B).

PARACYMBIUM. Elongated, sclerotized, with irregular margin, a beak-like basal outgrowth and a claviform distal outgrowth in retrolateral view (Figs 1C, 2B).

BuLB. With a semicircular subtegulum and a sheet-like membrane, the distal division sulciform, rolls up to protect the embolus (Figs 1B-C, 2A-B).

EmBoLus. Slender, band-shaped, with a pointed end (Figs 1B, 2A).

\title{
Female
}

Unknown.

\section{Distribution}

China (Guizhou, Fig. 7).

\author{
Mimetus lingbaoshanensis sp. nov. \\ urn:1sid:zoobank.org:act:ECE10654-7C1C-421A-813C-04B124DA67CA
}

Figs $3-4,7$

\section{Differential diagnosis}

The male of this new species resembles that of M. echinatus Wang, 1990 (Wang 1990: figs 3B-C, 4A-B; Zeng et al. 2016: figs 1B-C, 2A-B), but can be distinguished from the latter by: 1) vexillum of cymbium handle-like in retrolateral view (Figs 3D, 4B) versus sheet-like in M. echinatus (Zeng et al. 2016: figs 1B-C, 2A-B); 2) apex of cymbium without macrosetae (Figs 3C-D, 4A-B) versus present in M. echinatus (Zeng et al. 2016: figs 1B-C, 2A-B). The female of the new species resembles that of $M$. labiatus Wang, 1990 (Yin et al. 2012, figs 53C-D), but can be distinguished from the latter by: 1) scape of epigyne subtriangular in ventral view (Figs 3F, 4C) versus almost trapezoid in M. labiatus (Yin et al. 2012: figs 53c-d); 2) spermathecae round in dorsal view (Figs 3G, 4D) versus oval in M. labiatus (Yin et al. 2012: figs 53c-d).

\section{Etymology}

The specific name refers to the type locality: the Lingbaoshan National Forest Park. 


\section{Type material}

\section{Holotype}

CHINA - Õ; Yunnan, Nanjian County, Wuliangshan Township, Lingbaoshan National Forest Park; $24^{\circ} 45^{\prime} 47^{\prime \prime} \mathrm{N}, 100^{\circ} 30^{\prime} 10^{\prime \prime}$ E; $2285.1 \mathrm{~m}$; 12 Aug. 2015; Cheng Wang, Zhao-lin Liao, Gao-tao Liu and Peng Luo leg.; YN-MIM-2015-010.

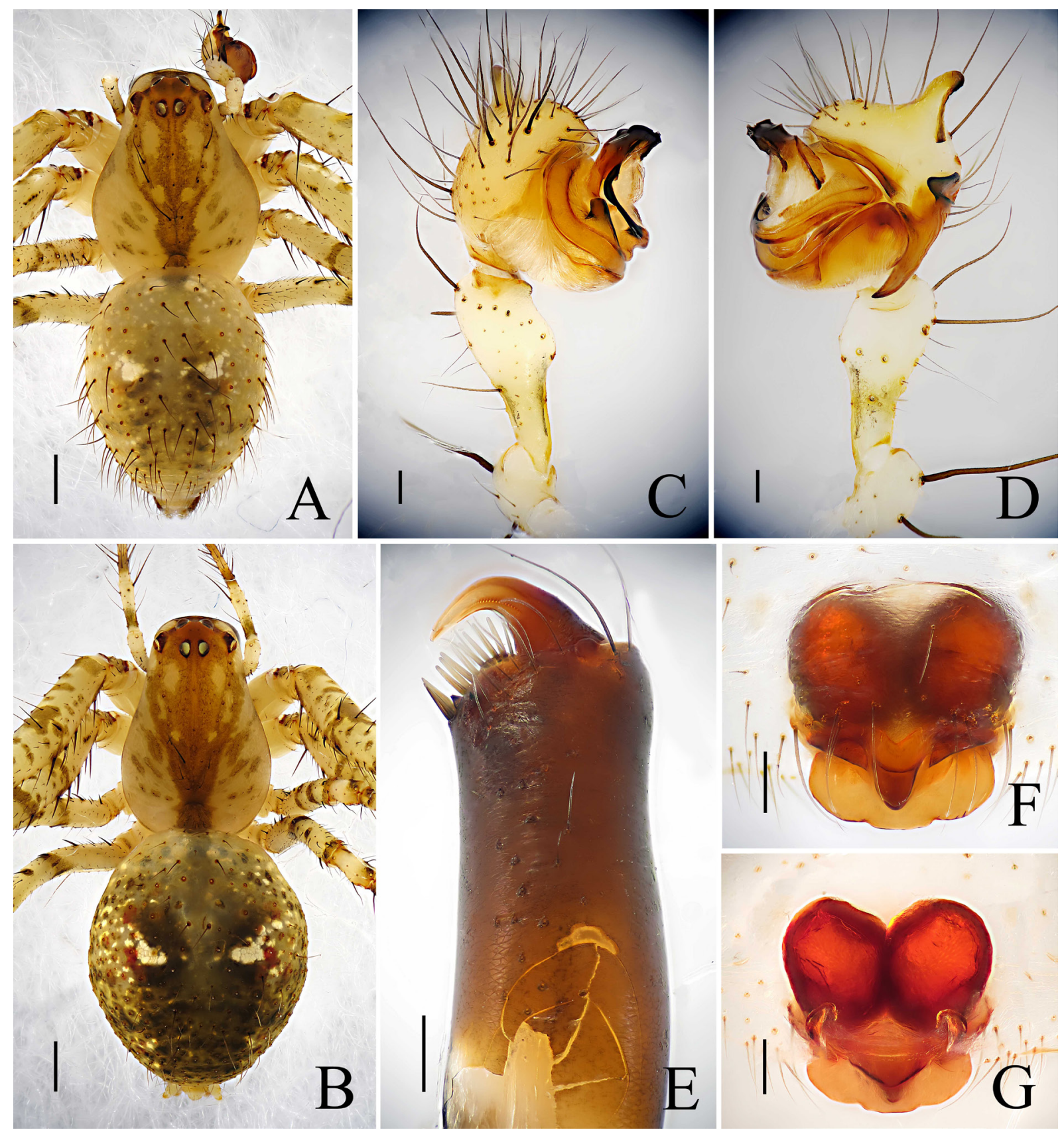

Fig. 3. Mimetus lingbaoshanensis sp. nov. A, C-E. Holotype, $ぇ(Y N-M I M-2015-010)$. B, F-G. One of the paratypes, o (YN-MIM-2015-011). A-B. Habitus, dorsal view. C. Palp, prolateral view. D. Palp, retrolateral view. E. Left chelicerae, ventral view. F. Epigyne, ventral view. G. Vulva, dorsal view. Scale bars: $\mathrm{A}-\mathrm{B}=0.5 \mathrm{~mm} ; \mathrm{C}-\mathrm{G}=0.1 \mathrm{~mm}$ 
Paratypes

CHINA • 1 §ิ, 3 우; same data as for holotype male; YN-MIM-2015-011,YN-MIM-2015-014.

\section{Description}

Male (holotype)

MeAsurements. Total length 4.27.

Prosoma. 2.18 long, 1.64 wide, oval, pale yellow, dorsally with a longitudinal brown patch and three rows of spines medially, and three pairs of greenish patches posteriorly, fovea oval, situated posteriorly (Fig. 3A).

\section{CLypeus. 0.22 high.}

EYE. Sizes and interdistances: AME 0.15, ALE 0.21, PME 0.22, PLE 0.21, AME-AME 0.06, ALE-AME 0.07, PME-PME 0.04, PME-PLE 0.20. MOA anterior width 0.9, posterior width 0.95, length 0.38 .

Chelicerae (Figs 3E, 4E). Red-brown, with 10 promarginal peg setae and 2 retromarginal teeth. Endites and labium light yellow, longer than wide.

STERnUm. Pear-shaped, glabrous, colouration as labium except for the margin with few macrosetae.

Legs. Slim, spiniferous, with brown patches. Length of legs: I 19.43 (4.81, 6.92, 5.60, 2.10), II 14.64 (4.01, 4.91, 3.90, 1.82), III $9.42(2.93,3.05,2.00,1.44)$, IV $10.36(3.02,3.20,2.71,1.43)$. Leg formula: 1243.
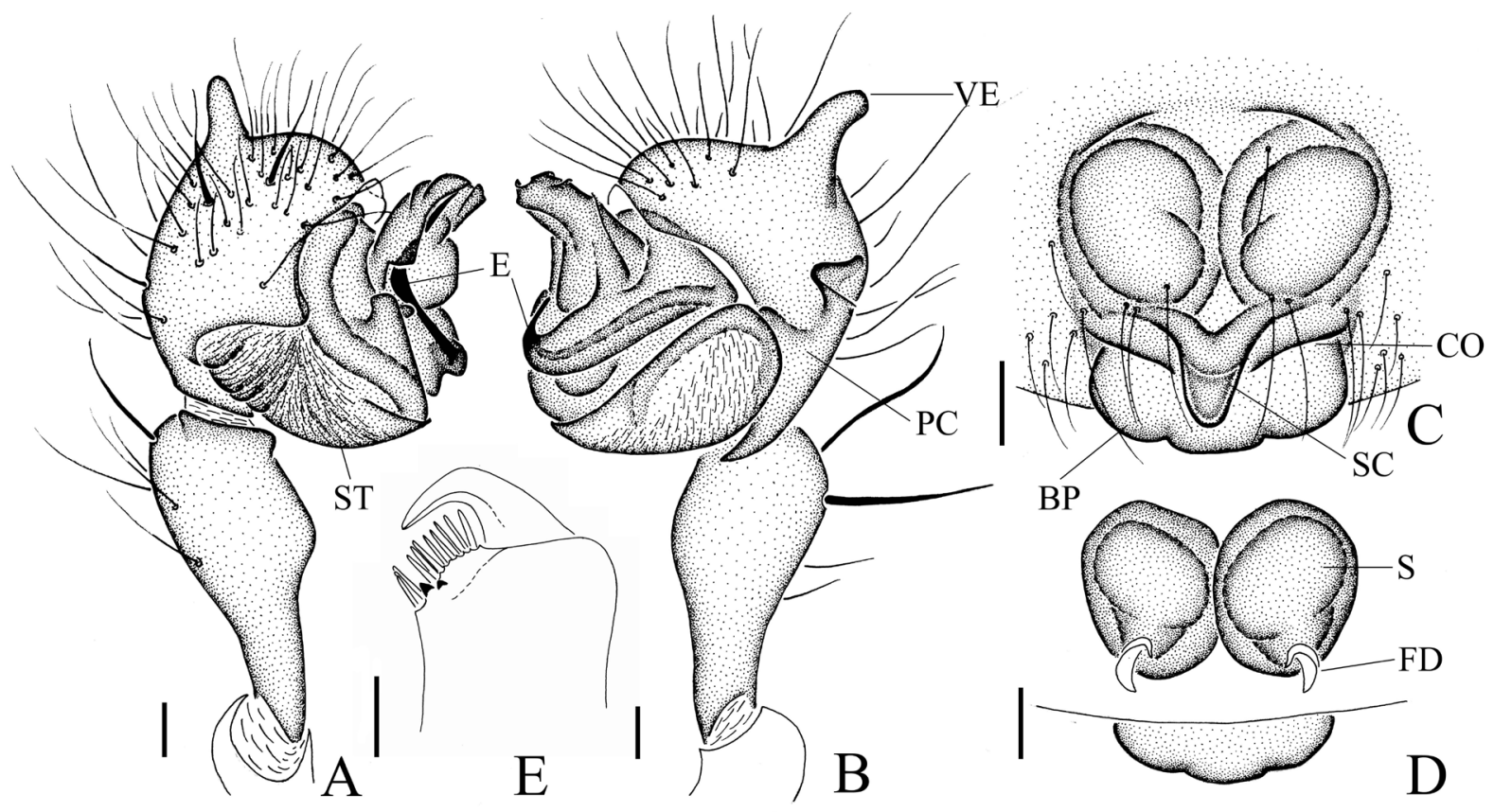

Fig. 4. Mimetus lingbaoshanensis sp. nov. A-B, E. Holotype, ô (YN-MIM-2015-010). C-D. Paratype, q (YN-MIM-2015-011). A. Palp, prolateral view. B. Palp, retrolateral view. C. Epigyne, ventral view. D. Vulva, dorsal view. E. Left chelicerae, ventral view. Scale bars $=0.1 \mathrm{~mm}$. 
Opisthosoma. 2.27 long, 1.82 wide, oval, dorsally with a pair of white patches and four pairs of brown patches posteriorly, covered with irregular white spots and sparse hairs (Fig. 3A); ventral side with three brown patches, median area grey, with white spots on lateral sides.

PALP. Tibia longer than wide, swollen at the distal end, with several trichobothria (Figs 3C-D, 4A-B).

Cyмвium. Slightly domed, with a handle-like vexillum distally (Figs 3C-D, 4A-B).

PARACYMBIUM. Elongate, distal part with a subtriangular outgrowth (Figs 3D, 4B).

Subtegulum. Semilunate. the distal division of bulb rolls up as sulciform to protect embolus (Figs 3C$\mathrm{D}, 4 \mathrm{~A}-\mathrm{B})$.

EmBoLus. Slender, broaden, band-shaped with a pointed end (Figs 3C, 4A).

Female (paratype YN-MIM-2015-011)

Measurements. Total length 4.59. Prosoma 2.19 long, 1.48 wide. Clypeus 0.21 high.

Prosoma (Fig. 3B). Yellowish brown, markings similar to those in the male.

EYE. Sizes and interdistances: AER 0.15, ALE 0.12, PME 0.15, PLE 0.15, AME-AME 0.14, AME-ALE 0.15 , PME-PME 0.10, PME-PLE 0.19. MOA anterior width 0.85 , posterior width 0.82 , length 0.36 .

Chelicerae. Endites and labium colourations as in the male. Chelicerae with 8 promarginal peg setae and 2 retromarginal teeth. Leg patches and spines are similar to those in the male. Length of legs: I 13.31 (3.61, 4.63, 3.42, 1.65), II 10.64 (3.07, 3.51, 2.68, 1.38), III 7.60 (2.42, 2.21, 1.74, 1.23), IV 9.11 (2.90, $2.96,2.25,1.00)$.
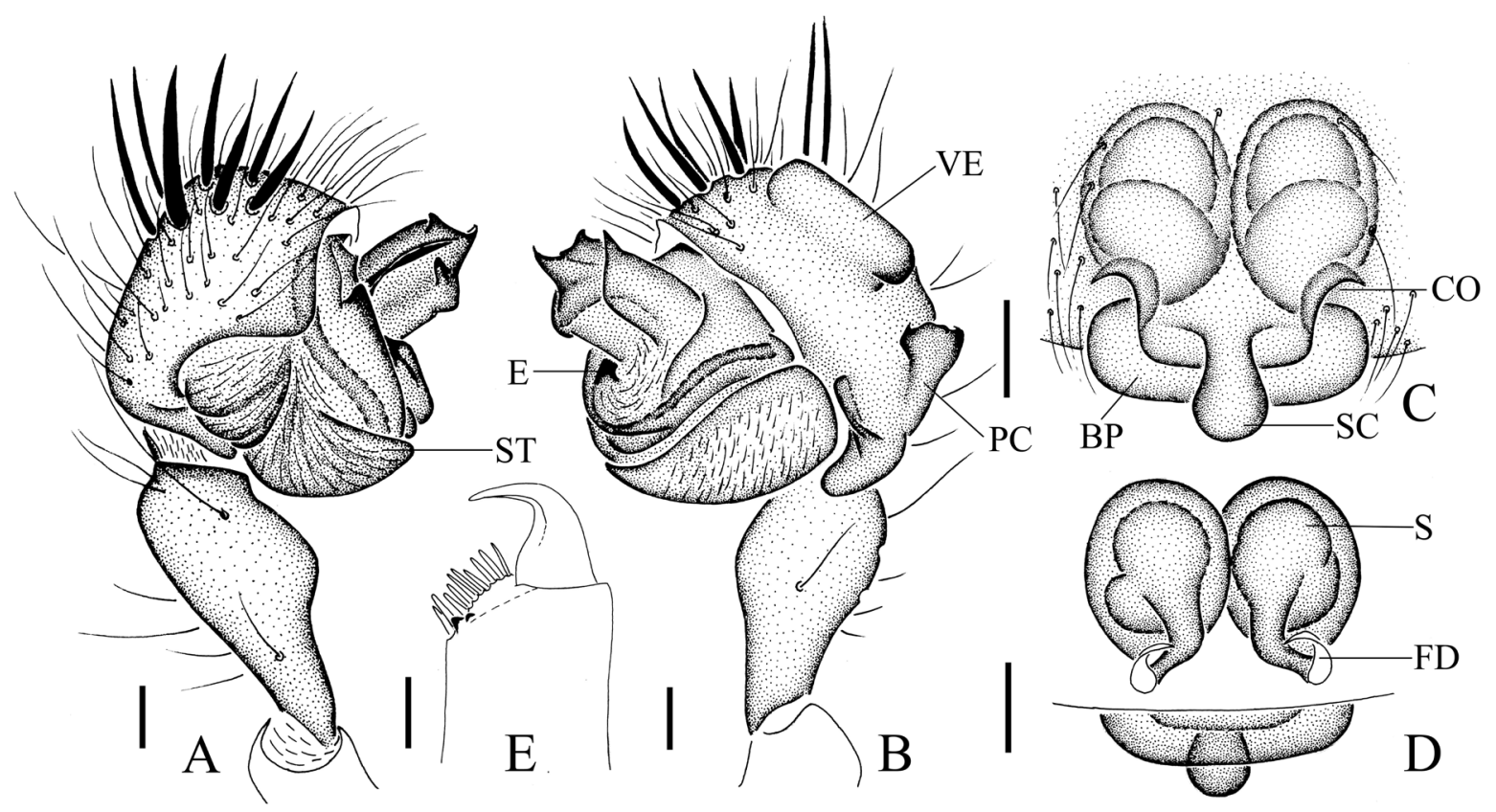

Fig. 5. Mimetus yinae sp. nov. A-B, E. Holotype, $\widehat{\jmath}$ (GZ-MIM-2015-005). C-D. Paratype, $q$ (GZMIM-2017-001). A. Palp, prolateral view. B. Palp, retrolateral view. C. Epigyne, ventral view. D. Vulva, dorsal view. E. Left chelicerae, ventral view. Scale bars $=0.1 \mathrm{~mm}$. 
Opisthosoma. 2.50 long, 2.14 wide, morphologic characteristics similar to those in male except with the darker colour (Fig. 3B); ventral side is similar to that in male except with three dark patches.

Epigyne (Figs 3F-G, 4C-D). Slightly longer than wide, with a labiate basal plate about 2 times longer than wide (Figs 3F, 4C). Scape subtriangular, situated between the copulatory openings (Figs 3F, 4C).

Copulatory. Openings wide, round, separated by the distance of $1 / 3$ the basal plate width (Figs 3F, 4C). Spermathecae globular, touch each other medially (Figs 3G, 4D).

\section{Distribution}

China (Yunnan, Fig. 7).

$$
\begin{aligned}
& \text { Mimetus yinae sp. nov. } \\
& \text { urn:1sid:zoobank.org:act:07968710-4B81-4D8C-8DFC-24217A695889 }
\end{aligned}
$$

Figs $5-7$

\section{Differential diagnosis}

The new species resembles M. echinatus Wang, 1990, especially in the cymbial apex of male palp with several macrosetae and distal part of paracymbium with a subtriangular outgrowth (Wang 1990: figs 5A-B, 6C-D; Zeng et al. 2016: figs 1B-C, 2A-B), but can be distinguished from the latter by 1) vexillum of male palp columnar in retrolateral view (Figs 5B, 6D) versus sheet-like in M. echinatus (Zeng et al. 2016: figs 1B-C, 2A-B); 2) the structure of the distal division of bulb different; 3 ) scape of epigyne bell-shaped in ventral view (Figs 5C, 6F) versus trapezoid in M. echinatus (Zeng et al. 2016: figs 1B-C, 2A-B); 4) length of basal plate about 2.5 times of its width in ventral view (Figs 5C, 6F) versus about 4 times in M. echinatus (Zeng et al. 2016: figs 1B-C, 2A-B).

\section{Etymology}

The specific name is patronym in honour of prof. Changming Yin, one of the most famous Chinese arachnologists.

\section{Type material}

\section{Holotype}

CHINA • 今'; Guizhou, Jiangkou County, Dewang Township, Nanmuping Village, Fanjingshan National Nature Reserve, Nanmuping; 2751'41" N, 108³6'52" E; 897 m; 17 Jul. 2015; Cheng Wang, Mingyong Liao, Tian-jun Liu, Gao-tao Liu, Xing Kuang and Peng Luo leg.; GZ-MIM-2015-005.

\section{Paratypes}

CHINA • 2 우; same data as for holotype; GZ-MIM-2015-006,GZ-MIM-2015-007 • 1 , , Shibing County, Maxi Township, Bajiaoping Village; $27^{\circ} 18^{\prime} 8^{\prime \prime}$ N, 108 ${ }^{\circ} 5^{\prime} 55^{\prime \prime}$ E; 990 m; 13 Jul. 2017; Xiao-qi Mi, Cheng Wang, Feng-e Li, Gui-jie Tian and Hong Liu leg.; GZ-MIM-2017-001 • 2 우; Shiqian County,

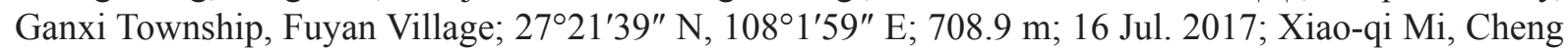
Wang, Feng-e Li, Gui-jie Tian and Hong Liu leg.; GZ-MIM-2017-002, GZ-MIM-2017-003.

\section{Description}

\section{Male (holotype)}

Measurements. Total length. 4.68.

Prosoma. 2.37 long, 2.01 wide, pear-shaped, yellow-brown, with a triangular brown patch, two pairs of yellow spots, and three pairs of white patches posteriorly, fovea oval, situated posteriorly (Fig. 6A). 
Clypeus. 0.25 high.

EYE. Sizes and interdistances: AME 0.21, ALE 0.15, PME 0.13, PLE 0.12, AME-AME 0.05, ALE-AME 0.07, PME-PME 0.11, PME-PLE 0.22. MOA anterior width 1.08, posterior width 1.05 , length 0.38 .

Chelicerae (Figs 5E, 6E). red-brown, with 10 promarginal peg setae and 2 retromarginal teeth.

ENDITES. Light yellow, longer than wide.
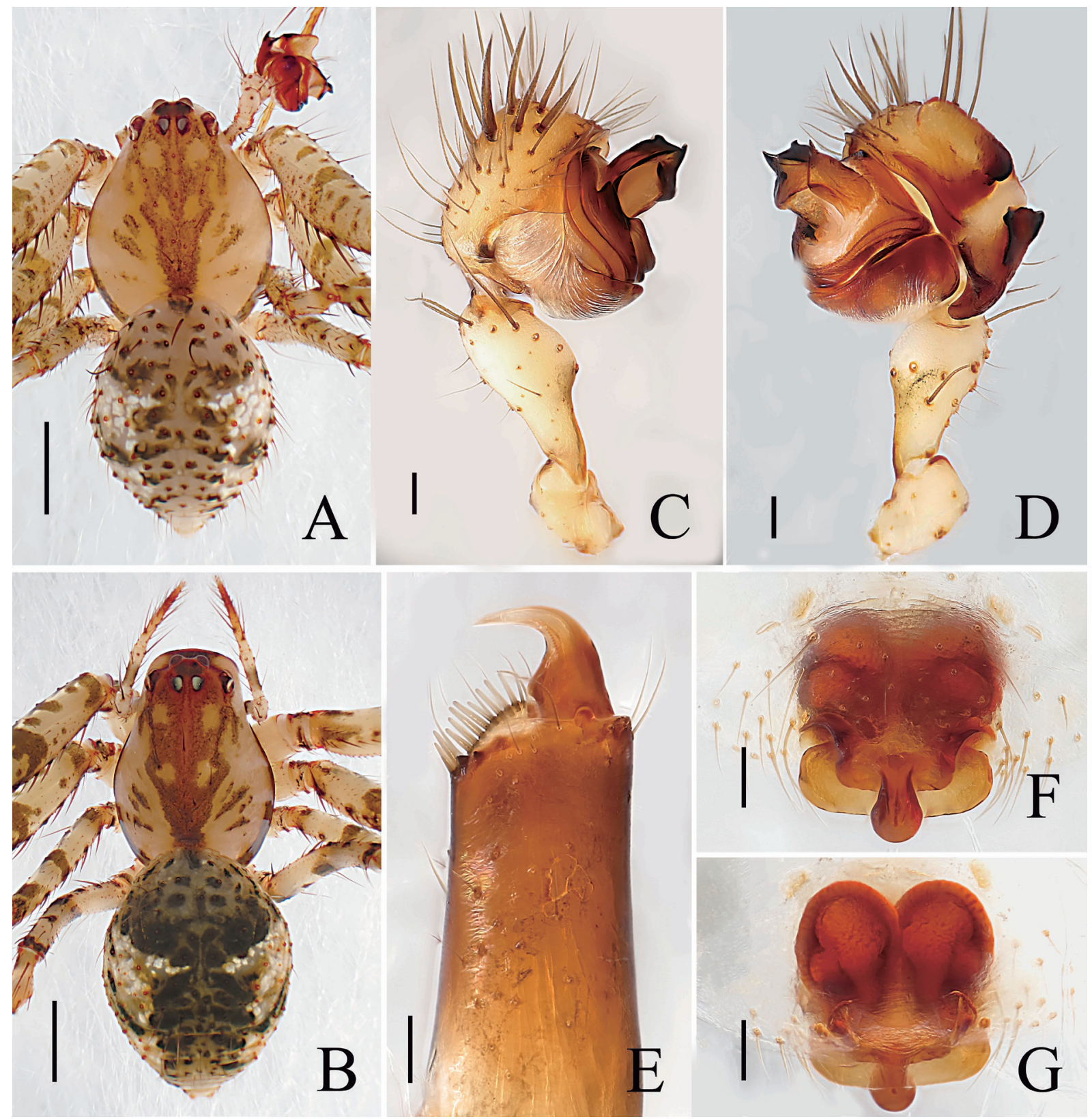

Fig. 6. Mimetus yinae sp. nov. A, C-E. Holotype, $\partial^{\lambda}$ (GZ-MIM-2015-005). B, F-G. Paratype, $q$ (GZMIM-2017-001). A-B. Habitus, dorsal view. C. Palp, prolateral view. D. Palp, retrolateral view. E. Left chelicerae, ventral view. F. Epigyne, ventral view. G. Vulva, dorsal view. Scale bars: A-B $=1.0 \mathrm{~mm}$; $\mathrm{C}-\mathrm{G}=0.1 \mathrm{~mm}$ 
LABIUM. Light yellow, longer than wide.

Sternum. Pear-shaped, glabrous, yellow, with few macrosetae on margin.

LEGS. Slim, spiniferous, with brown patches. Length of legs: I 13.19 (3.51, 4.32, 3.76, 1.60), II 9.76 $(2.48,3.42,2.35,1.51)$, III $6.26(1.97,1.93,1.21,1.15)$, IV $7.62(2.50,2.45,1.53,1.14)$. Leg formula: 1243.

Opisthosoma. 2.47 long, 1.98 wide, oval, with a pair of triangular white patches medially, and covered with brown dots and sparse hairs (Fig. 6A); ventral side with three brown patches, median area grey, glabrous, with white spots on both sides.

PaLP (Figs 5A-B, 6C-D).

Cymbium. Slightly domed, with a columnar vexillum, about 4 times longer than wide, and several macrosetae at the apex (Figs 5B, 6D).

PARACYMBIUM. Elongate, strongly sclerotized, slightly curved towards the bulb, with a subtriangular outgrowth distally (Figs 5B, 6D).

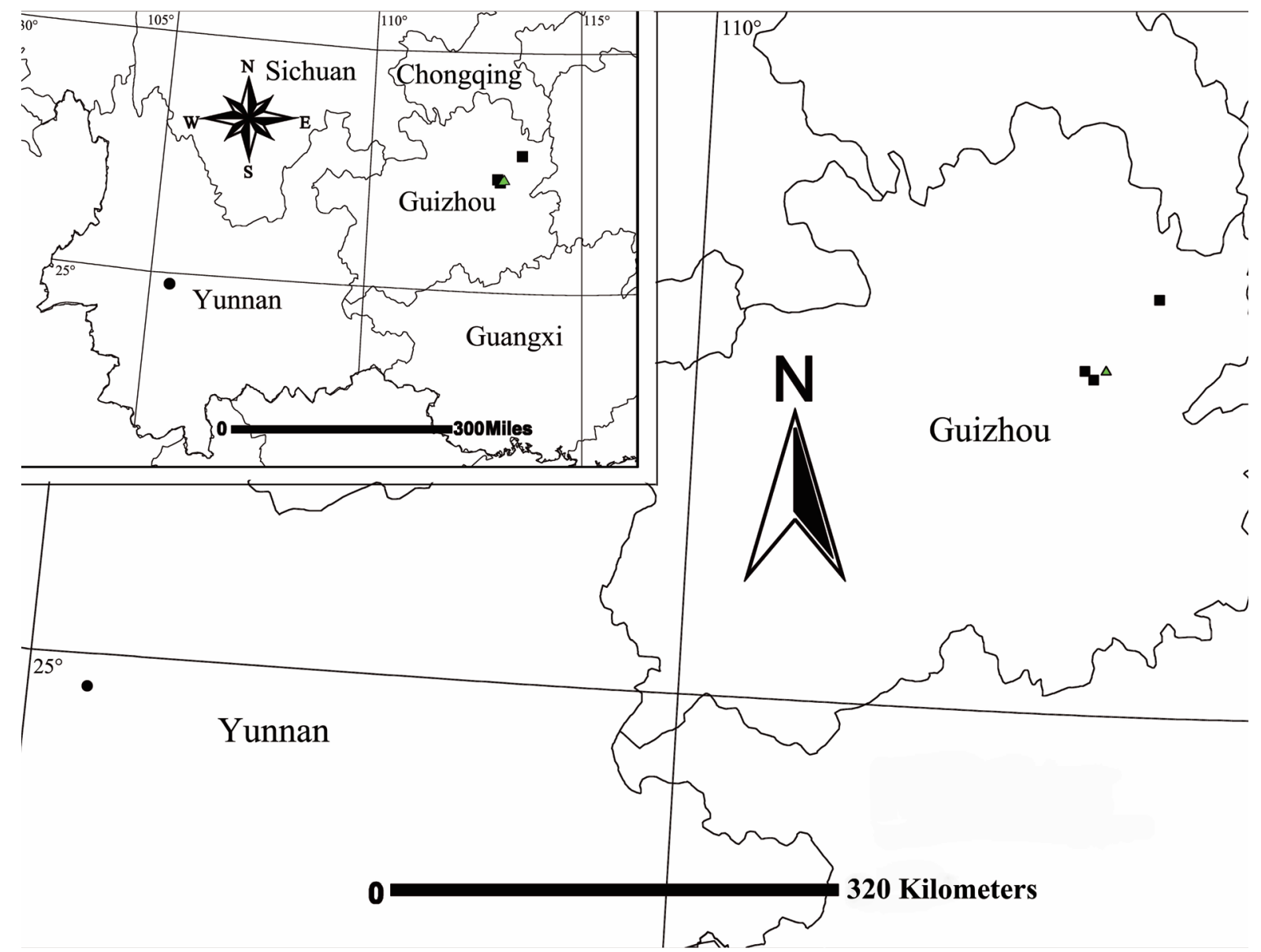

Fig. 7. Distribution records of Mimetus bucerus sp. nov. (\), M. lingbaoshanensis sp. nov. (•) and M. yinae sp. nov. (匹). 
Subtegulum. Semicircular; the distal division of bulb rolls up as sulciform to protect embolus (Figs 5A$\mathrm{B}, 6 \mathrm{C}-\mathrm{D})$.

EmBoLus. Slender, and terminal part covered by the distal division of bulb in prolateral view (Figs 5A, $6 C)$.

Female (paratype)

Measurements. Total length 5.33.

Prosoma. 2.72 long, 1.90 wide, yellowish brown, long oval, markings are similar to male (Fig. 6B).

CLYPeus. 0.21 high.

EYE. Sizes and interdistances: AER 0.20, ALE 0.23, PME 0.13, PLE 0.15, AME-AME 0.04, AME-ALE 0.11, PME-PME 0.10, PME-PLE 0.20. MOA anterior width 1.08, posterior width 1.12 , length 0.47 .

Chelicerae. Endites and labium colouration as in male. Chelicerae with 8 promarginal peg setae and 2 retromarginal teeth.

LEG. Patches and spines on legs are similar to those in male. Length of legs: I $12.61(3.01,4.35,3.53$, 1.72), II 10.47 (2.87, 3.31, 2.65, 1.64), III 6.48 (2.02, 1.71, 1.43, 1.32), IV 8.01 (2.60, 2.54, 1.75, 1.12).

Opisthosoma. 2.92 long, 2.31 wide, (Fig. 6B). Markings as those in male except for the darker colour; ventral side is similar to male except for three dark patches.

Epigyne (Figs 5C-D, 6F-G). Slightly longer than wide, basal plate big, concave and about 3 times longer than its width (Figs 5C, 6F). Scape bell-shaped, the terminal overlap the posterior margin of basal plate (Figs 5C, 6F). Copulatory openings cambered, posterior-bilaterally (Figs 5C, 6F). Spermathecae oval, touches each other medially (Figs 5D, 6G).

\section{Distribution}

China (Guizhou, Fig. 7).

\section{Discussion}

The three new species resemble the members of Australomimetus, Mimetus and Phobetinus in the shape and spine patterns of prosoma: cephalic elongated and mediolateral rows of spines oblique and reaching the fovea (a typical patterns of species of Australomimetus, Mimetus and Phobetinus) (Harms \& Dunlop 2009). However, the male palpal cymbium of members of Australomimetus and Phobetinus is without a 'vexillum' (members of Australomimetus without extensions, species of Phobetinus only with a distinct 'shovel', but without 'vexillum') while that of Mimetus members with a 'vexillum' (the 'vexillum' maybe autapomorphic for Mimetus only see Harms \& Dunlop 2009). The male palpal cymbium of the three new species described in this paper has a distinct 'vexillum'. Moreover, the three new species also resemble the other species of Mimetus in the body shape and the structures of the genital organs. Based on the above mentioned characters, the three new species were identified as members of the genus Mimetus.

\section{Acknowledgements}

We are grateful to Cheng Wang, Ming-yong Liao, Zhao-lin Liao, Tian-jun Liu, Gao-tao Liu, Xing Kuang, Peng Luo, Gui-jie Tian, Hong Liu and Feng-e li for collecting the specimens. This research was sponsored by the National Natural Sciences Foundation of China (NSFC-31272271, 31272272, 31660609). It is also partly supported by the National Special Fund on Basic Research of Science and 
Technology of China (No. 2014FY110100), the Hunan Provincial Program for Development of Key Disciplines in Ecology (grant number No. 0713), the Biocorridor study of Fodingshan, Fanjingshan and Leigongshan, Science and Technology Cooperation Project Foundation of Guizhou province [grant number LH2016/7303, LH2017/7326], Natural Science Research Project Foundation of Guizhou Province of education [grant number KY2018/345], the Program for New Century Excellent Talents in University (NCET-12-0717) and the Hunan Provincial Innovation Foundation for Postgraduate (No. CX2017B182).

\section{References}

Harms D. \& Dunlop J.A. 2009. A revision of the fossil pirate spiders (Arachnida: Araneae: Mimetidae). Palaeontology 52: 779-802. https://doi.org/10.1111/j.1475-4983.2009.00890.x

Harms D. \& Harvey M.S. 2009. Australian pirates: systematics and phylogeny of the Australasian pirate spiders (Araneae: Mimetidae), with a description of the Western Australian fauna. Invertebrate Systematics 23: 231-280. https://doi.org/10.1071/is08015

Liang T.E. \& Wang J.F. 1991. A new species of spiders of the genus Mimetus in Xinjiang (Araneae: Mimetidae). Journal of the August $1^{\text {st }}$ Agricultural College 14: 61-62.

Song D.X. \& Zhu M.S. 1993. A new species of the genus Mimetus from China (Araneae: Mimetidae). Acta Zootaxonomica Sinica 18: 421-423.

Wang J.F. 1990. Study on the spiders of family Mimetidae from south China (Arachnida: Araneae). Acta Zootaxonomica Sinica 15: 36-47.

World Spider Catalog. 2019. World Spider Catalog. Natural History Museum Bern. Available from https://wsc.nmbe.ch, ver. 20.0 [accessed on 25 Mar. 2019].

Yin C.M., Peng X.J., Yan H.M., Bao Y.H., Xu X., Tang G., Zhou Q.S. \& Liu P. 2012. Fauna Hunan: Araneae in Hunan, China. Hunan Science and Technology Press, Changsha.

Zeng C., Wang C. \& Peng X.J. 2016. Three spider species of the genus Mimetus Hentz, 1832 (Araneae, Mimetidae) from China. ZooKeys 626: 125-135. https://doi.org/10.3897/zookeys.626.7918

Manuscript received: 19 January 2019

Manuscript accepted: 26 March 2019

Published on: 15 May 2019

Topic editor: Rudy Jocqué

Desk editor: Marianne Salaün

Printed versions of all papers are also deposited in the libraries of the institutes that are members of the EJT consortium: Muséum national d'Histoire naturelle, Paris, France; Botanic Garden Meise, Belgium; Royal Museum for Central Africa, Tervuren, Belgium; Royal Belgian Institute of Natural Sciences, Brussels, Belgium; Natural History Museum of Denmark, Copenhagen, Denmark; Naturalis Biodiversity Center, Leiden, the Netherlands; Museo Nacional de Ciencias Naturales-CSIC, Madrid, Spain; Real Jardín Botánico de Madrid CSIC, Spain; Zoological Research Museum Alexander Koenig, Bonn, Germany. 